\title{
FERRAMENTAS DE CONTROLE DE BENS DE CONSUMO DISPONÍVEIS NO SIPAC E NO SIAFI: ESTUDO NA UNIVERSIDADE FEDERAL DO RIO GRANDE DO NORTE - UFRN
}

\author{
L. M. Batista, H. M. Batista, H. R. Hékis e L. B. Natale \\ Universidade Federal do Rio Grande do Norte \\ lidia23_10@yahoo.com.br
}

Artigo submetido em abril/2012 e aceito em janeiro/2013

\section{RESUMO}

O artigo tem por objetivo analisar as ferramentas disponíveis no Sistema Integrado de Patrimônio, Administração e Contratos - SIPAC que complementam os registros contábeis efetuados no Sistema Integrado de Administração Financeira do Governo Federal - SIAFI no controle dos bens de consumo da Universidade Federal do Rio Grande do Norte - UFRN. Para responder a este questionamento, realizou-se um levantamento bibliográfico acerca dos dois sistemas utilizados na referida instituição, iniciando com um breve histórico de cada um e, em seguida, trazendo uma explanação geral dos objetivos e das funcionalidades dos sistemas. A pesquisa foi exploratória, descritiva e avaliativa e o método estudo de caso, onde foi realizado um comparativo entre os principais relatórios utilizados no controle do Almoxarifado Central da Instituição disponibilizados pelos dois sistemas, a fim de identificar as possíveis informações complementares disponíveis no SIPAC. A partir desta constatação, conclui-se, que a implantação do SIPAC foi de grande relevância no controle dos bens de consumo dessa instituição de ensino superior por apresentar maiores informações sobre os itens armazenados no almoxarifado da UFRN.

PALAVRAS-CHAVE: Controle do almoxarifado, SIPAC, SIAFI.

\section{TOOLS CONTROL OF CONSUMER GOODS AVAILABLE ON SIPAC AND SIAFI: STUDY IN UNIVERSIDADE FEDERAL DO RIO GRANDE DO NORTE - UFRN}

\begin{abstract}
The article aims to analyze the tools available in the Sistema Integrado de Patrimônio, Administração e Contratos - SIPAC that complement the accounting records made in the Sistema Integrado de Administração Financeira do Governo Federal - SIAFI in control of consumer goods from the Universidade Federal do Rio Grande do Norte - UFRN. To answer this question, we carried out a literature survey about the two systems used in that institution, starting with a brief history of each and then bringing a general explanation of the objectives and features of the
\end{abstract}

systems. The research was exploratory and descriptive and evaluative case study method, where a comparison was made between the main reports used in the control of the Central Warehousing Institute offered by the two systems in order to identify possible additional information available on SIPAC. From this observation it is concluded that the implementation of SIPAC was of great importance in the control of consumer goods that institution of higher education by presenting more information about the items stored in the warehouse UFRN.

KEY-WORDS: Control of the warehouse, SIPAC, SIAFI. 


\section{FERRAMENTAS DE CONTROLE DE BENS DE CONSUMO DISPONÍVEIS NO SIPAC E NO SIAFI: ESTUDO NA UNIVERSIDADE FEDERAL DO RIO GRANDE DO NORTE - UFRN}

\section{INTRODUÇÃO}

A área pública, em sua gestão e controle, utiliza a contabilidade para acompanhar e controlar seu patrimônio. Os relatórios contábeis trazem informações que devem ser confiáveis e tempestivas. Com isso, a área pública precisa evidenciar tudo que envolva o controle de execução orçamentária, financeira e patrimonial, a fim de mostrar-se transparente com suas contas. Para isso, existem alguns sistemas contábeis utilizados pelos órgãos públicos, a fim de realizar o controle e apresentá-lo a todos os usuários interessados, de forma a ser transparente.

O sistema utilizado pelo Governo Federal (Sistema Integrado de Administração Financeira do Governo Federal - SIAFI) é o principal sistema para controle interno de cada Unidade Gestora pertencente ao governo, uma vez que é obrigatória a prestação de contas através desse sistema. O SIAFI realiza o controle de execução orçamentária, financeira e patrimonial no tocante ao controle patrimonial dos bens de consumo a cargo do almoxarifado. Porém, o referido sistema controla apenas os valores em moeda.

Já o Sistema Integrado de Patrimônio, Administração e Contratos - SIPAC é um sistema complementar criado pela Universidade Federal do Rio Grande do Norte - UFRN para ampliar o controle interno dessa Instituição. O SIPAC realiza o controle físico, com valores unitários e totais dos bens de consumo. Além disso, possui mais algumas ferramentas que complementam o controle efetuado pelo SIAFI.

Diante do exposto, surge o questionamento que a pesquisa investiga: Quais ferramentas de controle de bens de consumo do almoxarifado da UFRN o SIPAC dispõe para complementar o controle realizado pelo SIAFI?

A partir da pergunta de pesquisa do estudo, faz-se necessário alinhar as seguintes hipóteses, ou seja, HO: não há diferença entre as ferramentas de controle do almoxarifado utilizadas nos dois sistemas e $\mathrm{H} 1$ : há diferença entre as ferramentas de controle do almoxarifado utilizadas nos dois sistemas.

O objetivo geral desta pesquisa é analisar quais ferramentas de controle de bens de consumo do almoxarifado o SIPAC dispõe para complementar o controle realizado pelo SIAFI.

Como justificativa, destaca-se que é a de que todo cidadão tem o direito de ter acesso às contas do governo a fim de observar o que é feito com o dinheiro público. Além disso, os órgãos públicos precisam ter um controle minuncioso de todo o seu patrimônio, como também do orçamento e das finanças.

O SIAFI traz as informações relevantes para o atendimento dessas necessidades. Porém, a UFRN desenvolveu um sistema para complementar as informações encontradas no SIAFI e para facilitar o controle do patrimônio (no significado geral da palavra) da Instituição.

O presente estudo visa contribuir para um melhor entendimento sobre os dois sistemas utilizados no controle do almoxarifado da UFRN, a fim de mostrar a importância desses sistemas para os seus usuários e para a sociedade em geral. 
O artigo está estruturado da seguinte maneira, ou seja, a primeira seção trata da introdução, a segunda seção versa sobre a fundamentação teórica, a terceira seção apresenta os procedimentos metodológicos utilizados, a quarta seção traz a descrição e a análise dos dados e os resultados, a quinta seção apresenta a conclusão e recomendações e, em seguida, são relacionadas as referências utilizadas.

\section{Fundamentação teórica}

\subsection{SIAFI - Sistema integrado de administração financeira do governo federal}

Consoante o anexo à Instrução Normativa no 03/2001 Capítulo I, o SIAFI, "é o sistema informatizado que registra, controla e contabiliza toda a execução Orçamentária, Financeira e Patrimonial do Governo Federal, em tempo real". (BRASIL, 2001, p.1).

Porém, para que o SIAFI viesse a ser implantado no Brasil, foram observados diversos fatores relevantes na administração pública, e, de acordo com as necessidades do governo, foi-se elaborando um sistema capaz de auxiliar no controle das finanças públicas.

Assim, ainda de acordo com o Portal SIAFI (BRASIL, 2012), para facilitar o trabalho dessas UGs, cada ano equivale a um sistema, que, para obter acesso, o usuário deverá colocar SIAFI acrescido do ano que ele deseja consultar ou trabalhar (este só é possível no ano vigente).

\subsubsection{Objetivos e funcionalidade}

Segundo a Instrução Normativa no 03/2001 (BRASIL, 2001), são objetivos do SIAFI: proporcionar à Administração Pública uma forma adequada de controlar diariamente a execução orçamentária, financeira e contábil; tornar o controle finaceiro dos recursos do Tesouro Nacional mais eficientes; fazer da Contabilidade Pública uma fonte segura para a tomada de decisões; integrar as informações a todos os órgãos que utilizem o sistema; prover a transparência dos gastos públicos; permitir o acompanhamento analítico do orçamento; auxiliar no controle do patrimônio dos Estados e Municípios e de suas entidades supervisionadas através dos registros contábeis e prover o controle da dívida externa e interna do Governo Federal, assim como das transferências voluntárias.

Conforme a Lei das Diretrizes Orçamentárias do Governo Federal (BRASIL, 2005), a obrigação de utilização do SIAFI engloba os órgãos da administração direta, as autarquias, as fundações e outras entidades controladas que recebam recursos financeiros do seu controlador a fim de quitar despesas com pessoal ou de custeio em geral ou de capital, desde que este não seja por aumento de participação acionária.

\subsubsection{Documentos contábeis de entrada e de saída de dados}

Consoante Feijó, Pinto e Mota (2008), há diversos documentos de Entrada de Dados que são lançados no SIAFI. Como o presente estudo limitou-se ao Almoxarifado Central da UFRN, foram pesquisados os documentos de Entrada de Dados ulitizados no controle do Almoxarifado, que são a Nota de Empenho - NE, a Nota de Lançamento - NL e a Nota de Lançamento de Sistema - NS.

É através da tela inicial (Figura 1) que o usuário tem acesso às informações contidas no SIAFI. Ou o usuário marcará um " $x$ " na opção desejada, ou colocará em "comando" o código de acesso às informações desejadas, que serão apresentadas a seguir. 


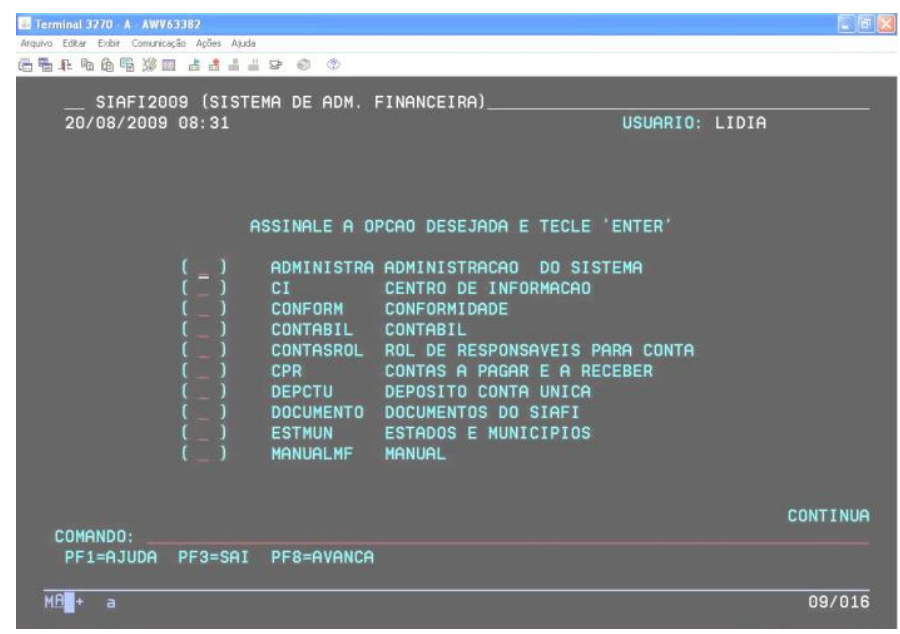

Figura 1 - Tela inicial - SIAFI

Fonte: https://acesso.serpro.gov.br/

É por meio da NE que é registrado o primeiro estágio das despesas orçamentárias, em que terá o nome do credor, a especificação do material, a importância da despesa e a célula orçamentária, deduzindo o saldo da dotação aprovada. Para o almoxarifado, a Nota de Empenho já estará disponível, sendo o interesse apenas para a consulta. A partir da NL são registrados os atos e fatos administrativos que não possuam um documento específico. O comando específico para esse registro é o ">NL".

O lançamento de liquidação das despesas é feito através da NS. O comando para efetuar este registro é ">ATUCPR". A diferença de acesso ocorre pelo fato do comando CPR se referir às Contas a Pagar e a Receber, que serão atualizadas pelo lançamento da NS.

Com relação às consultas, Feijó, Pinto e Mota (2008, p. 35), dividem em dois tipos: a consulta sintética e a consulta analítica.

A consulta sintética é uma consulta "on-line" que mostra informações que foram atualizadas até um dia útil anterior à data da consulta. Através da consulta sintética é possível acessar o Balancete do material de consumo do almoxarifado. Nesse caso, utiliza-se a opção ">BALANCETE" na tela de comando.

Já a consulta analítica, para Feijó, Pinto e Mota (2008 p. 35), é uma "consulta 'on-line' que apresenta informações atualizadas até 0 instante em que foi solicitada, pois utiliza os próprios arquivos onde são atualizados os movimentos diários das unidades gestoras". Através dessa consulta é possível obter mais detalhes para cada grupo de material de consumo, através do Razão de cada um. Para tal, utiliza-se o comando ">CONRAZAO".

Também há a possibilidade de consulta aos documentos de entrada de dados. Para fazê-lo, basta colocar ">CON" antes das respectivas siglas. Ex: ">CONNS" para realizar a consulta do lançamento de uma Nota Fiscal.

\subsection{SIPAC - sistema integrado de patrimônio, administração e contratos}

SINFO (2011, p.1) conceitua o SIPAC como o sistema "responsável pelo controle e gestão dos procedimentos administrativos da UFRN". Através desse sistema, há uma integração dos processos de contratação da universidade com o orçamento recebido pelo governo federal, uma vez que todos os setores da instituição utilizam o SIPAC. Esse sistema controla desde o orçamento disponibilizado pelo governo até o destino final dos recursos, sendo ele bens de consumo, bens móveis, livros, diárias, entre outros.

\subsubsection{Objetivos e Funcionalidade}


O SIPAC é um sistema em constante desenvolvimento, uma vez que, ele vai se adequando às necessidades de cada usuário, para aperfeiçoar o controle do patrimônio da Instituição. (CARDOSO, 2008).

Além do SIPAC, foram criados mais dois sistemas: Sistema Integrado de Gestão de Atividades Acadêmicas - SIGAA e o Sistema Integrado de Gestão de Planejamento e de Recursos Humanos SIGPRH. Diferentemente dos sistemas iniciais, esses novos sistemas possuem um portal na internet em que o acesso é feito pelos usuários cadastrados conforme sua participação na Universidade. (SINFO, 2009).

A Figura 2 é traz a ligação entre os sistemas e a idéia principal de cada um.

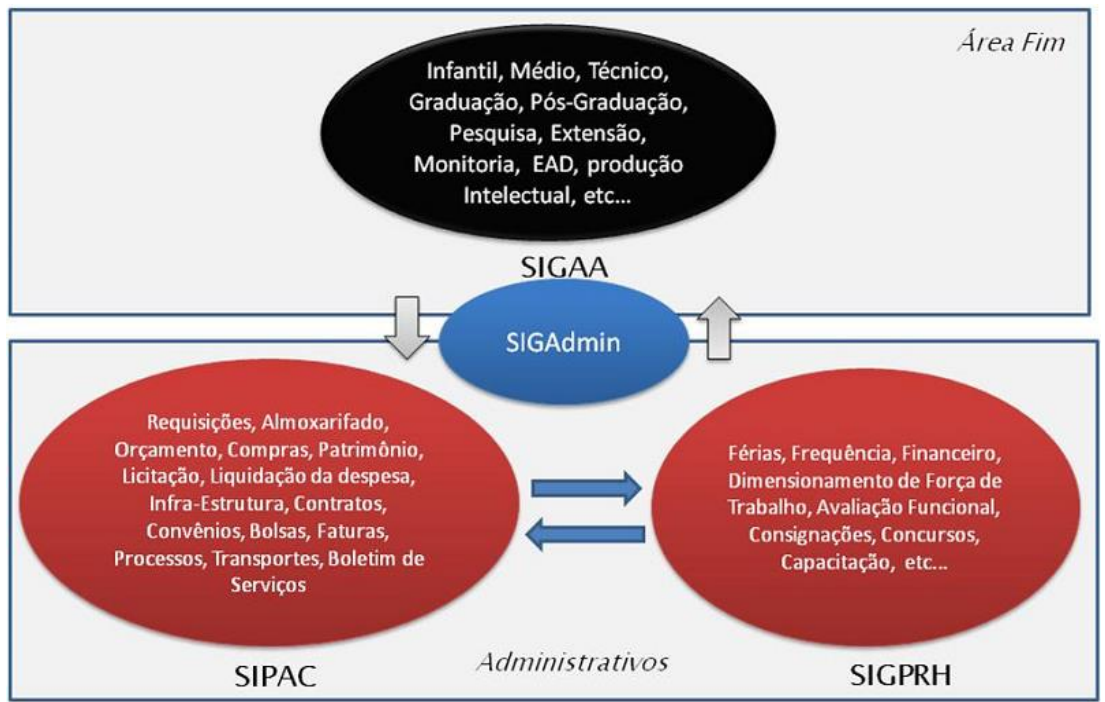

Figura 2 - Áreas de abrangência dos sistemas Fonte: SINFO (2009)

De acordo com Lima (2009), o sistema está em contínuo desenvolvimento, pois ele se adequa às necessidades do usuário, a fim de facilitar e agilizar o trabalho.

Conforme Lima (2009), o governo repassa uma verba que irá para o orçamento da universidade. Através do SIPAC essa verba é distribuída para as unidades de custo, observando as necessidades delas. $E$, então, tudo se inicia na requisição, seja de material de consumo ou permanente, bens, diárias, entre outros. Depois de enviada a requisição, os passos necessários serão seguidos até a entrega do material na unidade requisitante.

$\mathrm{Na}$ área administrativa do SIPAC também é possível encontrar o controle de estoque de material nos almoxarifados central e setoriais (unidades que compõem a UFRN). $O$ orçamento recebido pelo governo, que é registrado no sistema já dividido pelas unidades segundo as suas necessidades, é descontado a cada requisição atendida e a cada outro gasto efetuado. (SINFO, 2009).

Quando é elaborada uma requisição, o sistema já realiza o bloqueio do valor referente a ela no orçamento preestabelecido. Assim, quando há a realização da despesa (feita através do empenho), o centro de custo possui orçamento suficiente para custeá-la. No caso de não haver saldo, será fundamental a autorização do gestor responsável pelo orçamento daquele setor, a fim de prosseguir com a solicitação. Com isso, facilita o controle orçamentário dos centros de custos da unidade gestora para várias requisições existentes. Este vínculo orçamentário é chamado Fluxo Orçamentário. (SINFO, 2009). 
As requisições são relacionadas a um empenho ligado ao módulo orçamentário. Assim, quando o empenho é registrado, o valor contingenciado é liberado e o débito é realizado no centro de custo segundo as informações contidas no empenho. (SINFO, 2009)

\subsubsection{Almoxarifado}

A SINFO (2009) conceitua os almoxarifados como local em que são armazenados os materiais de consumo que foram adquiridos pela universidade, a fim de, posteriormente, suprir as necessidades das unidades da instituição.

Conforme a SINFO (2009), para que os pedidos de material sejam atendidos, inicialmente o almoxarifado central precisará dar entrada no seu estoque. Essas entradas poderão ser de quatro formas: Nota Fiscal (é o documento entregue junto à mercadoria adquirida pelo almoxarifado), Entrada Avulsa (é feita quando o almoxarifado é novo, onde a partir da primeira entrada, as outras serão registradas como Notas Fiscais), Nota de Fornecimento (quando o almoxado subordinado recebe o material, será feito o registro da entrada como nota de fornecimento, que equivale à requisição para o almoxarifado superior a esse) e devolução (quando o material volta ao almoxarifado de onde havia saído).

Ainda segundo a SINFO (2009), a Nota Fiscal deverá ser registrada no sistema com todas as informações contidas na Nota, como série, tipo, número, data de emissão e fornecedor - itens fundamentais para o cadastro no sistema.

O processo de liberação do valor contingenciado pode ser observado de forma resumida através da figura 3.

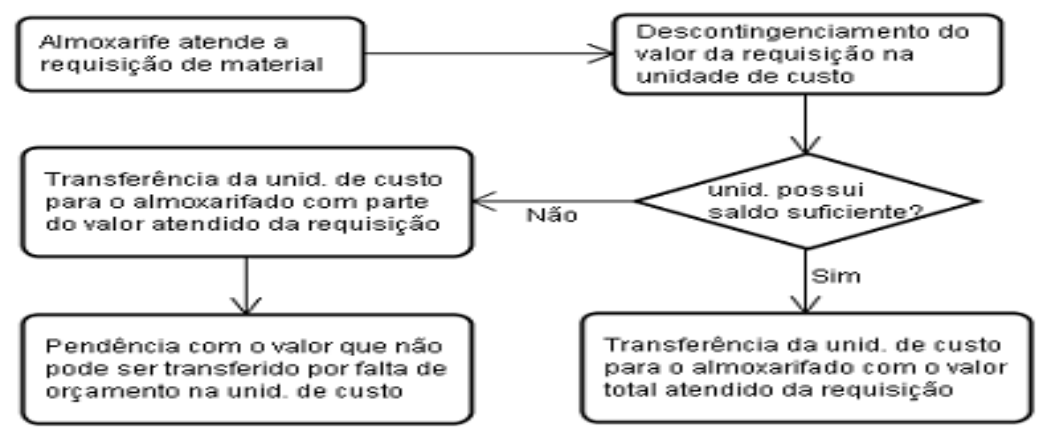

Figura 3 - Operações Orçamentárias no Atendimento da Requisição de Material Fonte: SINFO (2009)

\section{Procedimentos metodológicos}

A pesquisa tem fins exploratórios, tendo como meios de investigação a pesquisa bibliográfica em livros, periódicos e endereços eletrônicos ligados ao tema exposto, bem como uma pesquisa de campo para colher informações sobre o sistema interno da Universidade, uma vez que há um conteúdo mínimo escrito sobre ele. (VERGARA, 2005).

No presente trabalho, de acordo com Vergara (2005), a amostra estudada não foi probabilística, mas por acessibilidade, uma vez que foram utilizados elementos de fácil acesso. A instituição escolhida foi a UFRN, que se caracteriza como o universo da pesquisa. Como amostra, a comparação entre o SIPAC e o SIAFI foi feita utilizando apenas o controle dos bens de consumo (almoxarifado), facilitando a realização do estudo.

Nesta pesquisa, segundo Vergara (2005), o procedimento de coleta utilizado foi a pesquisa bibliográfica. A pesquisa de campo foi feita por meio de uma entrevista informal 
com um dos criadores do SIPAC, a fim de obter mais informações sobre a funcionalidade do sistema, uma vez que não há material impresso sobre ele que possa auxiliar na pesquisa.

Por se tratar de um novo tema, o referencial obtido se limitou à bibliografia disponível e à entrevista efetuada.

\section{Análise da Realidade Investigada: Sistemas SIPAC e SIAFI na Universidade Federal do Rio Grande do Norte - UFRN}

\subsection{Aspectos operacionais do setor de Material e Patrimônio}

Segundo Diogo, Amaral e Vieira (2008), a UFRN possui unidades que emitem requisições de materiais para compra destes ou para serem atendidas pelo almoxarifado central. Para isso, faz-se necessário possuir saldo orçamentário e autorização expressa da autoridade competente.

No Departamento de Material e Patrimônio (DMP) há uma comissão que analisa os trabalhos desenvolvidos pelo Almoxarifado e controla as entradas e saídas de materiais. O Almoxarifado Central da Instituição fica responsável pelo controle do almoxarifado através do SIPAC, enquanto que o DMP apropria a Nota Fiscal, bem como os lançamentos de baixa de material e transferência no SIAFI. (DIOGO; AMARAL; VIEIRA, 2008).

Além disso, a mesma comissão responsável por esses lançamentos faz a conferência das informações registradas no SIPAC e no SIAFI, a fim de confrontar os valores e prezar pela correta apresentação dos valores dos bens de consumo do Almoxarifado Central.

Assim, é possível observar que há um controle detalhado das entradas e das saídas do Almoxarifado Central da UFRN, de forma que, mês a mês, é feito o fechamento das contas do almoxarifado central, comparando os dados informados no SIAFI e no SIPAC.

$\mathrm{Na}$ primeira tela do SIPAC, o usuário colocará seu login e sua senha para ter acesso às informações contidas no Sistema. Efetuado o login, o usuário terá acesso à tela dos módulos disponibilizados pela Superintendência de Informática conforme solicitação da chefia do departamento ou da unidade.

Após efetuar o login, o usuário terá acesso à tela dos módulos. A SINFO Superintendência de Informática disponibiliza o acesso aos módulos conforme solicitação da chefia do departamento ou da unidade. Os módulos disponíveis ao usuários são aqueles que se encontram na cor azul, conforme a figura 4.

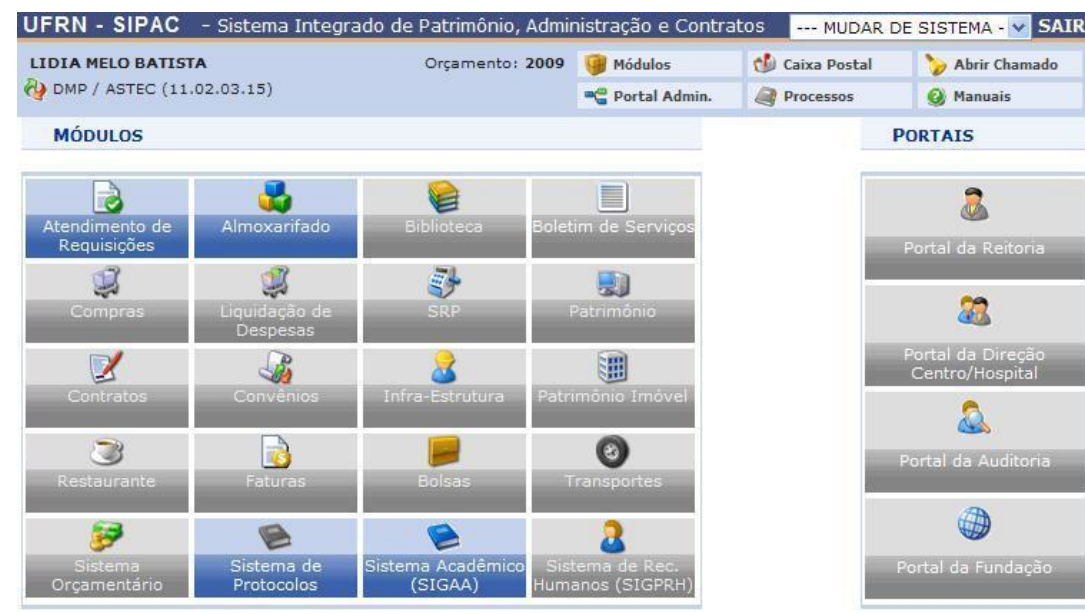

Figura 4 - Módulos do SIPAC 


\section{Fonte: https://www.sipac.ufrn.br/sipac/}

Escolhido o módulo, o sistema estará estruturado em abas, para uma melhor organização.

No módulo almoxarifado, o usuário poderá efetuar os registros de entradas de material, como também consultá-las (e seus respectivos empenhos). No caso das saídas de material, utiliza-se a aba requisições. Nela, o usuário poderá efetuar os registros das saídas de material e poderá imprimir, depois, o relatório de atendimento das requisições.

$\mathrm{Na}$ aba Relátórios, o usuário poderá consultar uma lista de todas as notas fiscais que foram registradas no sistemas, como também uma lista das requisições atendidas, divididas pelas unidades de custos requisitantes e um relatório com todas as movimentações de cada grupo. Outro relatório importante é o RMA Sintético (Relatório de Movimentação do Almoxarifado). Esse relatório equivale ao balancete de material de consumo do SIAFI. Ou seja, é esse o relatório utilizado para confrontar com os dados contidos no balancete do SIAFI.

\subsection{Descrição e análise dos dados e resultados encontrados}

Para que seja possível encontrar as ferramentas que complementam o controle dos bens de consumo, faz-se necessária uma análise profunda de pelo menos um grupo de material. Com isso, fez-se uma comparação do controle efetuado através dos dois sistemas.

Assim, a Figura 5 apresenta um relatório disponível no SIPAC com as movimentações do grupo 3019, que se trata de Material de Acondicionamento e Embalagem.

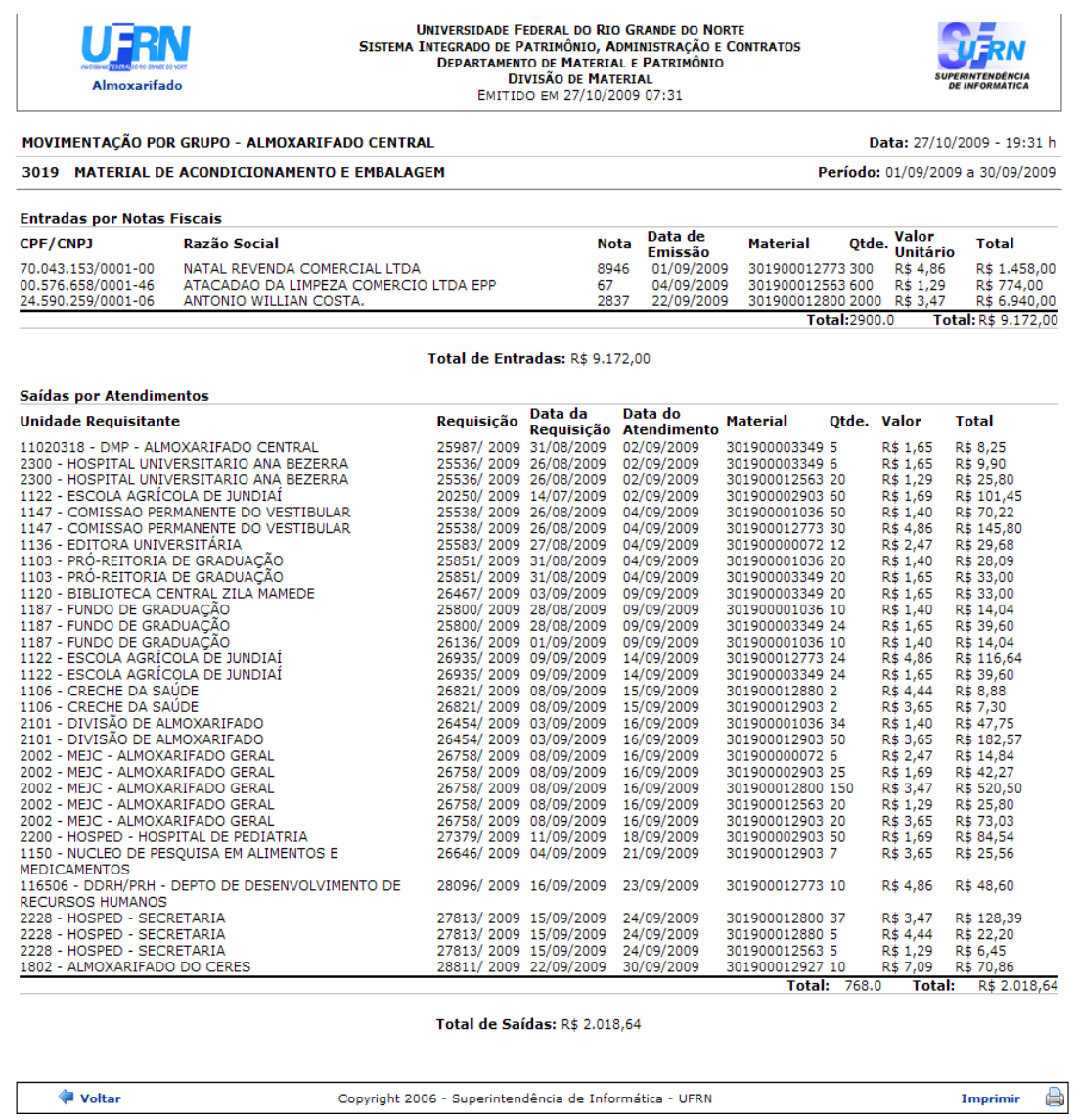

Figura 5 - SIPAC - Relatório Movimentação por Grupo 


\section{Fonte: https://www.sipac.ufrn.br/sipac/}

Outro relatório que o SIPAC disponibiliza para controlar as entradas e saídas por grupo de material é o Relatório de Movimentação do Almoxarifado - RMA Analítico.

O controle desse grupo é efetuado no SIAFI através dos lançamentos contábeis. Assim, para efetuar a comparação, é mostrado o razão, conforme Figura 6.

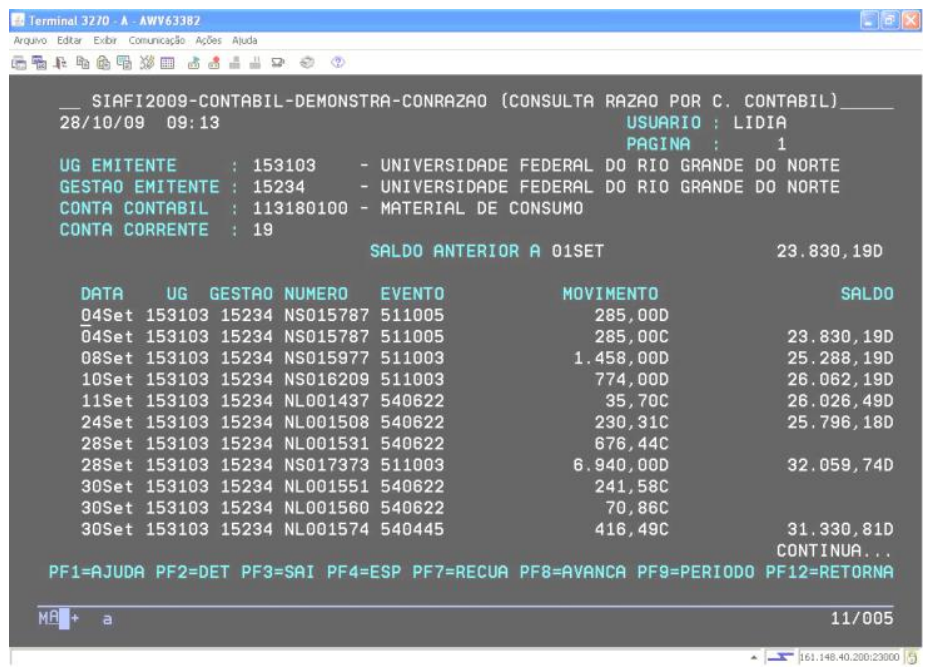

Figura 6 - Razão do SIAFI

Fonte: https://acesso.serpro.gov.br/

Assim, através da comparação entre os relatórios RMA - Analítico e Relatório de Movimentação por Grupo disponíveis no SIPAC e o Razão do SIAFI, é possível perceber que o SIPAC apresenta uma complementação do registro contábil efetuado no SIAFI, disponibilizando mais detalhes sobre os itens que entraram e saíram do almoxarifado, incluindo especificações, quantidades de entrada e saída e o saldo restante, valores unitários, valores totais das entradas e saídas por item e valores totais das entradas e saídas por grupo.

O SIPAC também apresenta um relatório que pode ser comparado ao balancete disponibilizado pelo SIAFI (conforme Figuras 7 e 8). 


\begin{tabular}{|c|c|c|c|c|c|c|c|}
\hline & 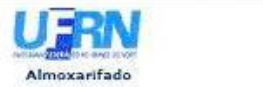 & \multicolumn{5}{|c|}{$\begin{array}{l}\text { UNIVERSIDADE FEOERAL DO RIO GRANDE DO NORTE } \\
\text { SISTEMA INTEGRAD DE PATRIMOONIO, ADMINISTRAÇAO E CONTRATOS } \\
\text { SUSTENTAC,AO DE ESTOQUE DO ALMOXARIFADO CENTRAL } \\
\text { EMITIDO EM 30/10/2009 03:41 }\end{array}$} & 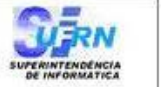 \\
\hline \multicolumn{8}{|c|}{ RELATÓRIO dE MOVIMENTAÇĀo do ALMOXARIFADO - RMA SINTÉtICO } \\
\hline \multicolumn{8}{|c|}{2009} \\
\hline & & & \multicolumn{2}{|c|}{ Entradas } & & & \\
\hline Código & Denominação & Saldo Anterior (Rs) & Entradas (RS) & Ent. Extra (Rs) & Saidas (RS) & Devoluçōes (Rs) & Saldo Atual (RS) \\
\hline 3003 & $\begin{array}{l}\text { COMBUSTIVEIS E } \\
\text { LUBRIFICANTES P/ OUTRAS } \\
\text { FINALIDADES }\end{array}$ & $5.256,56$ & 0,00 & 0,00 & 677,16 & 0,00 & $4.579,40$ \\
\hline 3004 & GAS ENGARRAFADO & $290.593,17$ & 0,00 & 0,00 & $1.546,45$ & 0,00 & $289,046,72$ \\
\hline 3007 & GENEROS DE ALIMENTACAO & $58.586,41$ & $10.846,24$ & 0,00 & $13.759,58$ & 0,00 & $55.673,07$ \\
\hline 3016 & MATERLAL DE EXPEDIENTE & $686.097,40$ & $31,450,33$ & 0,00 & $59.650,51$ & 0,00 & $657,897,22$ \\
\hline 3017 & $\begin{array}{l}\text { MATERLAL OE PROCESSAMENTO } \\
\text { OE DADOS }\end{array}$ & $476.435,59$ & $77.491,22$ & 0,00 & $53.817,68$ & 0,00 & $500.109,13$ \\
\hline 3019 & $\begin{array}{l}\text { MATERIAL DE } \\
\text { ACONDICIONAMENTO E } \\
\text { EMBALAGEM }\end{array}$ & $23.830,19$ & $9.172,00$ & 0,00 & $2.018,64$ & 0,00 & $30.983,55$ \\
\hline 3021 & MATERIAL DE COPA E COZINHA & $123.165,94$ & $8.100,00$ & 0,00 & $14.400,16$ & 0,00 & $116,865,78$ \\
\hline 3022 & $\begin{array}{l}\text { MATERIAL DE LIMPEZA E } \\
\text { PRODUTOS DE HIGIENIZACAO }\end{array}$ & $312.237,00$ & $49.456,90$ & 0,00 & $46.499,08$ & 0,00 & $315,194,82$ \\
\hline 3024 & $\begin{array}{l}\text { MATERIAL PARA MANUTENCAO } \\
\text { DE BENS IMOVEIS }\end{array}$ & 1,96 & 0,00 & 0,00 & 0,00 & 0,00 & 1,96 \\
\hline 3025 & $\begin{array}{l}\text { MATERLAL PARA MANUTENCAO } \\
\text { DE BENS MOVEIS }\end{array}$ & 421,21 & 0,00 & 0,00 & 0,00 & 0,00 & 421,21 \\
\hline 3026 & MATERIAL ELETRICO & 11,18 & 0,00 & 0,00 & 0,00 & 0,00 & 11,18 \\
\hline 3028 & $\begin{array}{l}\text { MATERIAL DE PROTECAO E } \\
\text { SEGURANCA }\end{array}$ & $11,310,33$ & 0,00 & 0,00 & $1.090,83$ & 0,00 & $10.219,50$ \\
\hline 3029 & $\begin{array}{l}\text { MATERIAL PARA AUDIO, VIDEO } \\
\text { E FOTO }\end{array}$ & $2.764,96$ & 0,00 & 0,00 & 0,00 & 0,00 & $2.764,96$ \\
\hline 3036 & MATERIAL HOSPITALAR & 0,00 & 0,00 & 0,00 & 0,00 & 0,00 & 0,00 \\
\hline \multirow[t]{2}{*}{3041} & $\begin{array}{l}\text { MATERIAL P/ UTILIZACAO EM } \\
\text { GRAFICA }\end{array}$ & 229,96 & 0,00 & 0,00 & 120,48 & 0,00 & 109,47 \\
\hline & Total: & \multicolumn{4}{|c|}{ RS $1.990 .941,86$ RS $186.516,69$} & R\$ 0,00 & R\$ $1.983 .877,97$ \\
\hline & voltar & Copyright 2006 - & Superintendéncis & de Informática - 4 & UFRN & & Imprimir 19 \\
\hline
\end{tabular}

Figura 7 - Balancete do SIPAC

Fonte: https://www.sipac.ufrn.br/sipac/

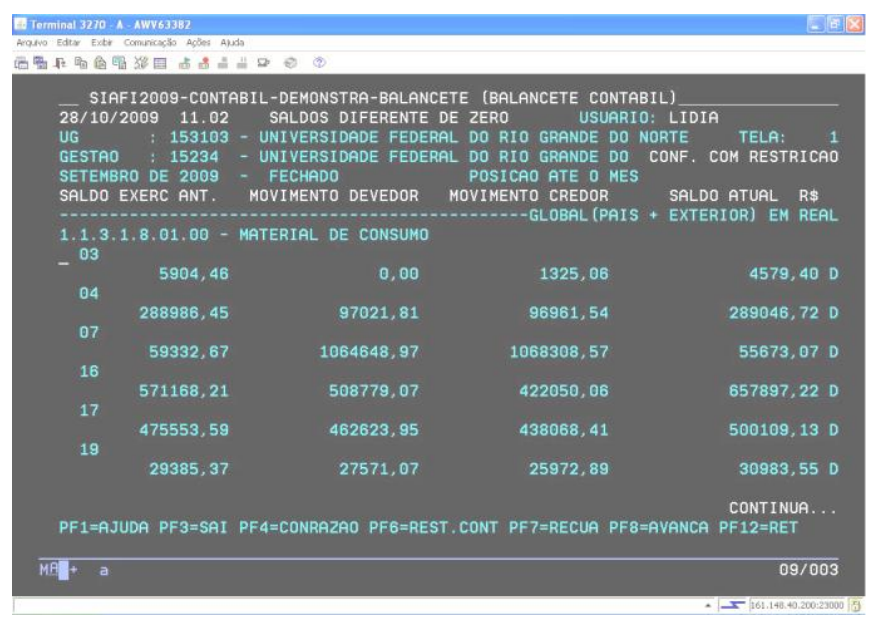

Figura 8 - Balancete do SIAFI

Fonte: https://acesso.serpro.gov.br/

Comparando o RMA - Sintético do SIPAC e o Balancete do SIAFI, é possível observar que o SIPAC apresenta um detalhamento mensal, especificando o saldo do mês anterior, as entradas orçamentárias e extra-orçamentárias, as saídas e as devoluções, identificando, também, o nome do grupo a qual pertencem.

Já o SIAFI apresenta as movimentações de janeiro ao mes ao qual foi solicitado o balancete, apresentando o saldo final do ano anterior, e as entradas e as saídas de janeiro até o mês solicitado. A última coluna de ambos os relatórios apresenta o saldo final do mês solicitado. É essa coluna que é comparada mensalmente, pois os dois sistemas necessitam estar sempre em compatibilidade. 
Além disso, o SIPAC possui outras ferramentas para consulta que também auxiliam no controle interno dos materiais do almoxarifado da Universidade.

Na aba Estoque, o usuário poderá consultar cada requisição efetuada, as notas de empenhos, as Notas Fiscais dos materiais entregues, as entradas e saídas avulsas, os materiais disponíveis em outro almoxarifado (setoriais ou Central), as notas fiscais extornadas e o processo de compra após a Licitação. Já na aba requisições, o usuário poderá consultar os relatórios de atendimento e de devolução. Já na aba Relatórios é onde o usuário poderá ter informações sobre a movimentação, sobre o material e sobre dados gerais.

No tópico movimentação da aba Relatórios, tem-se o RMA analítico e sintético, a movimentação por material ou por grupo de material, as entradas por Nota Fiscal, as requisições atendidas/negadas (onde tem-se informação do valor total das requisições atendidas total ou parcialmente, negadas ou devolvidas, e um gráfico para melhor visualização), oferta e demanda de materiais em estoque (onde observa-se as médias de consumo por mês nos últimos 2 anos de todos os materiais cadastrados no almoxarifado) e saídas por perdas (onde mostra os materiais que saíram do almoxarifado por serem inservíveis ou por terem desaparecido).

No tópico material, tem-se o estoque mínimo (com o valor do saldo real e o saldo mínimo necessário para cada material), os materiais sem saldo (apresenta os itens que estão com o saldo zerado), os materiais mais solicitados (em que lista os materiais mais pedidos para cada unidade durante o período determinado e a quantidade atendida), os materiais a vencer (apresenta os itens que estão próximos a vencer, especificando o prazo de validade), o total dos materiais solicitados e atendidos por unidade (lista todas as unidades que solicitaram material selecionado durante o período determinado e a quantidade de material solicidado e atendido por cada unidade) e o histórico das entradas (com os preços dos materiais nas últimas compras efetuadas).

No tópico gerais/Unidade o usuário pode obter o relatório de consumo geral ou por unidade (em que traz uma média do consumo diário, mensal e semestral e o consumo total de cada item), o relatório de etiquetas de prateleira (que apresenta o saldo, em valor, de cada material e seu respectivo código), o relatório de despesas da unidade (onde mostra todos os materiais solicitados pelas unidades durante o período selecionado, com quantidades e valores unitários e totais por grupo), requisições atendidas por unidade (em que apresenta uma listagem de todos os materiais solicitados durante o período solicitado, separados por unidade e por requisição), devoluções da unidade (em que apresenta os itens que foram devolvidos ao almoxarifado) e o relatório sintético de despesas por unidade (onde tem-se os gastos de cada unidade com os diversos grupos de material durante o período determinado).

Assim, é possível observar que o SIPAC possui diversas ferramentas que auxiliam no controle do almoxarifado, complementando as informações apresentadas no SIAFI. Ou seja, a implantação do SIPAC na UFRN foi de grande relevância para a ampliação do controle dos bens de consumo da instituição.

\section{Conclusão e recomendações}

Este estudo evidenciou que o surgimento do SIAFI no Brasil teve a finalidade de integrar os sistemas de programação financeira, de execução orçamentária e de controle 
interno do Poder Executivo, para que a Administração Pública pudesse ter um melhor controle das informações gerenciais, sendo elas confiáveis e precisas.

Conclui-se deste modo, que o referido sistema tem como objetivos proporcionar uma contabilidade eficaz da Administração Pública, a fim de proporcionar informações fidedignas para tomada de decisão, bem como proporcionar a transparência dos gastos públicos, entre outros.

Também ficou evidente, que o SIAFI traz informações sobre os saldos de cada grupo de material existente no almoxarifado, sobre as notas fiscais lançadas, sobre as notas de empenho registradas, e sobre o valor das saídas de material. Já o SIPAC foi implantado com o intuito de dar suporte ao controle interno da UFRN, complementando as informações apresentadas pelo SIAFI e auxiliando na realização das atividades da Universidade. O sistema vem sendo aperfeiçoado para atender às necessidades de cada unidade e da universidade de um modo geral.

Por outro lado o SIPAC tem como objetivo dar suporte à universidade no que se refere à requisições, almoxarifado, orçamento, compras, patrimônio, liquidação da despesa, infra-estrutura, contratos, convênios, bolsas, faturas, processos, transportes e boletim de serviços.

Dessa maneira conclui-se que o SIPAC apresenta as mesmas informações contidas no SIAFI e as complementa com valores mais específicos para cada grupo de material, bem como quantidades de cada material, o valor unitário e total, apresenta relatórios para ampliar o controle do material existente em estoque e o que foi disponibilizado para as unidades e subunidades da universidade através das requisições.

Em segundo lugar, conclui-se que os sistemas, SIAFI e SIPAC, são muito importantes para o controle do almoxarifado da UFRN. O primeiro possui o tratamento contábil, com valores financeiros, enquanto que o segundo apresenta um maior detalhamento das movimentações de cada item, especificando o item, a quantidade, os valores unitários, os saldos por item e outras informações extraídas das consultas de Notas Fiscais, de Notas de Empenho e de Requisições Atendidas, dos Relatórios de Movimentação do Almoxarifado (analítico e sintético), dos Relatórios de Movimentações por Grupo de Material e por Material, do Relatório de Requisições atendidas por Unidade (bem como o Relatório de Despesas da Unidade), dos Relatórios de Consumo Geral ou por Unidade, do Relatório de Entradas por Nota Fiscal, entre outros.

Recomenda-se, dessa maneira, a realização de novos estudos acerca do SIPAC e sua contribuição, não só para outras áreas abrangidas pelo SIAFI, como também para outros sistemas do Governo Federal tais como SIAPE, SCDP, dentre outros.

Por fim, conclui-se que o uso do SIPAC é de grande relevância como um controle complementar do SIAFI, uma vez que, através dele, é mais fácil obter informações claras, mais detalhadas e precisas sobre os bens de consumo existentes em uma instituição.

\section{REFERÊNCIAS BIBLIOGRÁFICAS}

1. BRASIL. Instrução normativa no 03 de 23 de maio de 2001. Brasília: Secretaria do Tesouro Nacional. 
<http://manualsiafi.tesouro.fazenda.gov.br/040000/042100/0421 03>. Acesso em: $10 \mathrm{abr}$ 2012.

2. BRASIL. Lei no 11.178, de 20 de setembro de 2005. Brasília: Secretaria do Tesouro Nacional. Disponível em: <http://www.planalto.gov.br/ccivil_03/_ato20042006/2005/Lei/L11178.htm> . Acesso em: 10 abr 2012.

3. BRASIL. Portal SIAFI. Brasília: Secretaria do Tesouro Nacional. Disponível em: <http://www.stn.fazenda.gov.br/siafi/index_conheca_siafi.asp>. Acesso em: 10 abr 2012.

4. CARDOSO, A. B. Gestão de patrimônio: uma abordagem dos registros do material permanente, nos sistemas SIAFI e SIPAC, para execução do controle patrimonial da Universidade Federal do Rio Grande do Norte, um estudo de caso. 2008, 74 f. Monografia (Bacharelado em Ciências Contábeis) - Universidade Federal do Rio Grande do Norte, Natal, 2008.

5. DIOGO, L.; AMARAL, N. N. A. do; VIEIRA, Z. M. R. A. Tomada de contas do almoxarifado central da UFRN. Natal, 2008.

6. FEIJÓ, P. H.; PINTO, L. F.; MOTA, F. G. L. Curso de siafi: uma abordagem prática de execução orçamentária e financeira. 2. ed. Brasília: Cidade Gráfica e Editora, 2008.

7. LIMA, R. G. F.. UFRN. Superintendência de Informática - SINFO. SIPAC - (Entrevista realizada com um dos criadores do Sistema Automatizado da UFRN. Em 17 ago 2009).

8. SINFO. Superintendência de Informática da UFRN-SINFO. SIPAC. 2009. (Acesso restrito aos gestores do Sistema Automatizado da UFRN - informações confidenciais para segurança do sistema. Dados utilizados para atividade acadêmica. Em 17 ago 2009).

9. SINFO. Sistemas Institucionais da UFRN: SIPAC, SIGAA e SIGPRH. Disponível em: <http://sistemasdaufrn.blogspot.com/>. Acesso em: 13 mar 2011.

10. VERGARA, S. C. Projetos e relatórios de pesquisa em administração. 6. ed. São Paulo: Atlas, 2005. 